\title{
Hemispheric asymmetry of development due to drug exposure
}

\author{
Harold W Gordon ${ }^{1 *}$ \\ ${ }^{1}$ Epidemiology Research Branch Division of Epidemiology, Services, and Prevention Research, National Institute on Drug Abuse, USA
}

\begin{abstract}
Background

A previous survey of the literature of fMRI brain activation for two risk factors, impulsivity and craving, for addiction were lateralized to the right and left hemispheres respectively. Most articles reported these findings without consideration of how lateral asymmetries might be relevant to understanding the underlying factors leading to addiction.
\end{abstract}

\section{Objective}

The current survey is intended to extend these observations by demonstrating hemispheric asymmetry of development due to pre-natal or adolescent/adult exposure to drugs of abuse.

Method

Articles that reported either pre-natal or adolescent/adult exposure to drugs of abuse were collected and the hemisphere of the affected structures was tabulated to determine if, and which, drugs affected more structures in one hemisphere or the other or both together.

Results

Some drugs, notably cocaine and alcohol, differentially affected left or right hemisphere structures which significantly differed depending on whether individuals were exposed prenatally or as an adolescent/adult. Cocaine tended to affect more left hemisphere structures when exposed prenatally and significantly affected more in the right when exposed as adults. Alcohol had the reverse pattern. The difference in patterns of effect between pre-natal or adult exposure was significant for both.

\section{Conclusion}

The results in this survey demonstrate that some drugs of abuse appear to have a right/left differential effect on structures of the brain. Further investigation into the reasons for this asymmetry may provide new insights into underlying factors of drug-seeking and addiction.

\section{Introduction}

For the understanding of addiction, the differential roles played by the structures and functions of the left and right hemispheres need more study. In a recent tabulation of cortical activation, impulsivity-a risk factor for addiction-and craving were found to differentially activate the right and left hemispheres, respectively [1] as is pointed out in that tabulation of over 100 articles. These observations are invariably reported in the literature but without discussion of what may differ in the right or left hemispheres to yield these observations. That is, tasks requiring individuals to be less impulsive by inhibiting prepotent responses (in tasks such as Stop Signal and Go/No-Go) produced more activation in the anterior segments in the right hemisphere than in the left. Less activation of these sites was seen in smokers [2], marijuana users [3] and cocaine users [4] suggesting increased impulsivity in these individuals. By contrast, cue-induced craving-e.g., showing a cue such as a picture of a substance craved by persons addicted to or dependent on a drug-more often activated areas in the left hemisphere. Are there hemispheric asymmetries in neurotransmitter levels? Are there hemispheric differences in neuronal connectivity? Are these differences genetically-driven? How do these neurobiological differences interact with drugs of abuse? In other words, what can we learn about these lateral differences that can illuminate the underlying factors of drug-seeking and addiction?

One way to answer these questions is to determine if each of these psychoactive drugs, themselves, have a differential effect on development of brain structures. If they do, one conclusion would be that the neurobiological environment was different causing the differential development. This can be studied in individuals who have had prenatal exposure to drugs of abuse or in individuals, who initiated drug-taking as adolescents or adults, and were scanned for morphological changes. If there are differences, then we can focus on the neurobiological events that may have enabled these drug effects. Such observations could give insight to brain damage or dysfunction associated with these drugs. Accordingly, the current study seeks to determine if drug exposure affects neuronal development or function

*Correspondence to: Harold W Gordon, Epidemiology Research Branch, Division of Epidemiology, Services, and Prevention Research, National Institute on Drug Abuse, 6001 Executive Boulevard, Room 5151, Bethesda, MD 20892, +1301 443-6504, USA, E-mail: hgordon1@nida.nih.gov

Received: April 02, 2017; Accepted: April 27, 2017; Published: April 29, 2017 
in more structures of one hemisphere than the other. It would be important to know whether each psychoactive substance has the same effect and whether timing-prenatal or adolescent/adult exposure-is critical.

\section{Method}

\section{Strategy of Tabulation}

Data were compiled from 114 studies reporting neuronal effects from exposure to drugs of abuse either prenatally (47 studies) or in adolescents or adults (67 studies). Lists of these studies were derived from PubMed using key words such as the name of the drug of interest, plus MRI, plus combinations of other key words: e.g., prenatal, morphology, laterality. For example, for prenatal exposure to cocaine, the key words were "cocaine; prenatal exposure; MRI"; also "PCE; MRI" (where PCE = prenatal cocaine exposure). For adult or adolescent exposure, an example would be "cocaine; morphology; MRI; laterality." For each study, the side (right, left, bilateral) and names of the affected structures were tabulated along with the type of effect: morphology (cortical thickness, gray matter volume, etc.) or abnormal neuronal activation. Each structure or brain area specified in the study was counted. Two tablulations, one for each time of exposure- prenatal or adolescent/adult-were made for each drug. For adolescent/adult exposure, participants were variously designated in the references as users, addicted, or dependent. While there are several changes in cortical and subcortical volume, connectivity, and activation during development from adolescence to adulthood [5], no asymmetrical (right/left) differences were seen [6]. Accordingly, it is recognized that drug exposure may differentially affect development between adolescents and adults; it presumed here that the hemispheric side of the effect would not change during those years. The main interest for this survey was to determine whether there was a right/left (or bilateral) side asymmetry in the number of those structures mentioned in the study. Unfortunately, in many of the studies considered here, specific structures were targeted (e.g., hippocampus) which would preclude an analysis to determine if there was a predominant effect on any one structure. Also, it was not possible to control or compensate for the different sizes of structures mentioned (e.g., superior temporal lobe vs. amygdala). This is justified to some extent because the underlying assumption of the consequences drug exposure is that the effect would be to a particular tissue or neuronal (structural) organization in one hemisphere regardless of size. Finally, articles did not differentiate effects on structures according to sex, so this could not be addressed.

For analysis, the expected null distribution would be that all structures would be affected bilaterally or at least there would be "random" right/left mentions averaging out to an equal numbers of mentions between the hemispheres, or, alternatively, an equal number of mentions among bilateral, right, and left hemispheres. Chi-square statistics assessed deviance from the expected equal distribution of mentions among the bilateral, right, and left hemispheres or, excluding bilateral, the distribution of right and left mentions.

The key questions of interest for prenatal and adolescent/adult exposure are 1) whether structures are bilaterally affected or whether structures are affected in one hemisphere more than the other, 2) if more structures are affected in one hemisphere, is it the right or left hemisphere, 3 ) if there is a side preference, is it the same for all drugs (i.e., a general effect of drug exposure not specific to a drug) or is there a different pattern of asymmetry (or lack of asymmetry) for each drug, and 4) across drugs, do the patterns of lateralized effect for prenatal exposure differ from the patterns for adolescent/adult exposure?

\section{Characteristics of Studies Included}

(References in Supplementary Material)

\section{Prenatal exposure}

Cocaine: A total of 8 studies included 338 participants that were tested as adolescents; 24 tested as children. Most studies observed (fMRI) activation abnormalities; others assessed cortical thickness or gray matter volume.

Nicotine: A total of 9 studies included 1205 participants. 228 were tested as young adults, 751 as adolescents; 226 as children. Six studies observed (fMRI) activation abnormalities, 3 assessed thickness abnormalities.

Alcohol: A total of 13 studies included 558 participants most of whom were tested as adolescents. Only 3 studies focused on activation; the remainder assessed cortical thickness or gray matter volume.

Cannabis: There were only 3 studies including 229 participants available for this survey. The largest study (167 participants) assessed cortical thickness; the others, brain activation.

Opioids: Only 1 study on 14 children ( 4 of whom had exposure to drugs in addition to heroin) could be analyzed for effects of prenatal exposure. Cortical thickness was assessed.

\section{Adolescent/adult exposure}

Cocaine: A total of 16 studies included 908 participants all of whom were assessed (and presumably exposed) as adults. Three studies assessed (fMRI) activation, 1 study assessed resting state functional connectivity; the rest assessed cortical thickness or gray matter volume.

Nicotine: A total of 11 studies included 1793 participants all tested as adults though exposure may have occurred during adolescence. With the exception of 2 studies that assessed fractional anisotropy, all studies assessed gray matter volume, density, or cortical thickness.

Alcohol: A total of 19 studies included 1504 participants. 313 were tested as adolescents; 217 as young adults; 974 as adults. Most studies assessed gray matter volume, 3 assessed cortical thicknesses and one assessed fractional anisotropy.

Cannabis: A total of 12 studies included 646 participants. 213 were tested as adolescents; 242 as young adults; 191 as adults. All studies assessed either gray matter volume or cortical thickness.

Opioids: A total of 9 studies included 461 participants all of whom were tested as adults. Five studies assessed gray matter density or volume, 1 assessed cortical thickness and 1 assessed neural activity and 1 assessed fractional anisotropy.

\section{Results}

\section{Pre-natal Exposure (Table 1)}

All drugs considered: Across all studies compiled for all drugs, together, the analysis showed no asymmetry whereby more affected structures were distributed among bilateral, right and left hemispheres. This means that there is no generalized asymmetry for drugs, per se, that affects the structures in one hemisphere, alone, or both hemispheres. However, the hemisphere distribution for pre-natal exposure to cocaine, nicotine, cannabis or alcohol was not the same for each drug. That is, the distribution of laterality patterns of structures affected across all drugs differed significantly $\left(\mathrm{X}^{2}=14.410, \mathrm{p}<.05\right)$ although the statistic is driven somewhat by the effect of cannabis; the distribution 
Table 1. Pre-natal exposure

\begin{tabular}{|c|c|c|c|c|c|}
\hline $\begin{array}{c}\text { DRUG/ } \\
\text { SIDE }\end{array}$ & $\begin{array}{c}\text { BILATERAL } \\
\text { (\# mentions } \\
\text { (\% of drug) }\end{array}$ & $\begin{array}{c}\text { LEFT } \\
\text { (\# mentions } \\
\text { (\% of drug) }\end{array}$ & $\begin{array}{c}\text { RIGHT } \\
\text { (\# mentions } \\
\text { (\% of drug) }\end{array}$ & $\begin{array}{c}\text { CHI- } \\
\text { SQUARE } \\
\text { (bilateral, } \\
\text { left, right) }\end{array}$ & $\begin{array}{c}\text { CHI- } \\
\text { SQUARE } \\
\text { (left, right; } \\
\text { bilateral } \\
\text { excluded) }\end{array}$ \\
\hline All drugs & $\begin{array}{c}48 \\
(26.8)\end{array}$ & $\begin{array}{c}63 \\
(35.2)\end{array}$ & $\begin{array}{c}68 \\
(38)\end{array}$ & $\begin{array}{c}\mathrm{X}^{2}=3.631 \\
\mathrm{NS}\end{array}$ & $\begin{array}{c}\mathrm{X}^{2}=0.191 \\
\text { NS }\end{array}$ \\
\hline Cocaine & $\begin{array}{c}12 \\
(30)\end{array}$ & $\begin{array}{c}17 \\
(42.5)\end{array}$ & $\begin{array}{c}11 \\
(27.5)\end{array}$ & $\begin{array}{c}\mathrm{X}^{2}=1.55 \\
\mathrm{NS}\end{array}$ & $\begin{array}{c}\mathrm{X}^{2}=1.286 \\
\mathrm{NS}\end{array}$ \\
\hline Nicotine & $\begin{array}{c}16 \\
(29.1)\end{array}$ & $\begin{array}{c}23 \\
(41.8)\end{array}$ & $\begin{array}{c}16 \\
(29.1)\end{array}$ & $\begin{array}{c}\mathrm{X}^{2}=1.782 \\
\mathrm{NS}\end{array}$ & $\begin{array}{c}\mathrm{X}^{2}=1.256 \\
\mathrm{NS}\end{array}$ \\
\hline Cannabis & $\begin{array}{c}0 \\
(0)\end{array}$ & $\begin{array}{c}8 \\
(44.4)\end{array}$ & $\begin{array}{c}10 \\
(55.6)\end{array}$ & $\begin{array}{c}\mathrm{X}^{2}=9.333 \\
\mathrm{p}<.01\end{array}$ & $\begin{array}{c}\mathrm{X}^{2}=0.222 \\
\mathrm{NS}\end{array}$ \\
\hline Opioids & $\begin{array}{c}0 \\
(0)\end{array}$ & $\begin{array}{c}0 \\
(0) \\
\end{array}$ & $\begin{array}{c}2 \\
(100)\end{array}$ & -- & -- \\
\hline Alcohol & $\begin{array}{c}20 \\
(31.5)\end{array}$ & $\begin{array}{c}15 \\
(23.4)\end{array}$ & $\begin{array}{c}29 \\
(45.3)\end{array}$ & $\begin{array}{c}\mathrm{X}^{2}=4.719 \\
\mathrm{p}<.10\end{array}$ & $\begin{array}{c}\mathrm{X}^{2}=4.455 \\
\mathrm{p}<.05\end{array}$ \\
\hline
\end{tabular}

Distribution: bilateral, left, right for cocaine, nicotine, cannabis, alcohol: $\mathrm{X}^{2}=14.410 ; \mathrm{p}<.05$

Distribution: bilateral, left, right for cocaine, nicotine, alcohol: $\mathrm{X}^{2}=7.016$; NS

Distribution: left, right for cocaine, nicotine, cannabis, alcohol: $\mathrm{X}^{2}=7.150 ; \mathrm{p}<.10$

Distribution: left, right for cocaine, nicotine, alcohol: $\mathrm{X}^{2}=6.988 ; \mathrm{p}<.05$

of patterns does not reach significance when cannabis is dropped from the analysis. But by dropping instances when drugs affected structures bilaterally-that is when comparing left vs. right structures-the distribution of asymmetry patterns is significant with $\left(\mathrm{X}^{2}=7.150, \mathrm{p}<\right.$ $.10)$ or without $\left(\mathrm{X}^{2}=6.988, \mathrm{p}<.05\right)$ including cannabis.

Cocaine: The analysis showed no significant bilateral, left, and right or left vs. right asymmetry for number of structures affected by pre-natal exposure to cocaine; there was a plurality favoring the left hemisphere.

Nicotine: The analysis showed no significant bilateral, right, and left or right vs. left asymmetry due to the effect of pre-natal exposure to nicotine.

Cannabis: Due to the absence of mentions for bilateral structures, the pattern including bilateral, left, and right is significant $\left(X^{2}=9.333\right.$, $\mathrm{p}<.01$ ), but not significant when "bilateral" is omitted.

Alcohol: There is a significant asymmetry for pre-natal exposure to alcohol: marginally for bilateral, left, right $\left(\mathrm{X}^{2}=4.719, \mathrm{p}<.10\right)$ and significantly for right vs. left $\left(\mathrm{X}^{2}=4.455, \mathrm{p}<.05\right)$. This is due to nearly twice as many reported effects for structures in the right hemisphere than in the left.

\section{Adolescent/adult Exposure (Table 2)}

All drugs considered: Across all studies compiled for all drugs, together, the analysis showed a marginal effect $\left(\mathrm{X}^{2}=5.012, \mathrm{p}<.10\right)$ for a bilateral, right, left distribution bias but no asymmetry for right vs. left. This appears to be due to fewer affected structures in both (bilateral) hemispheres than in left, and especially right, structures alone. Considering the pattern of laterality effects across the drugs, adolescent/ adult exposure, like pre-natal exposure, the distribution of affected structures by cocaine, nicotine, opioids, cannabis or alcohol exposure, was significantly different $\left(\mathrm{X}^{2}=15.832, \mathrm{p}<.05\right)$. To compare with the pattern for pre-natal exposure (where opioids were not included), the distribution remains significant for adolescent/adult when the effect of opioids is removed $\left(\mathrm{X}^{2}=13.902, \mathrm{p}<.05\right)$, but loses significance if cannabis is also removed. When only the right vs. left asymmetry is considered (omitting bilateral structures), the distribution pattern of asymmetries is marginally significant with all drugs included $\left(\mathrm{X}^{2}=\right.$ $8.383, \mathrm{p}<.10)$, or significant when omitting opioids $\left(\mathrm{X}^{2}=11.682, \mathrm{p}<\right.$ $.01)$ or omitting both opioids and cannabis. $\left(\mathrm{X}^{2}=6.751, \mathrm{p}<.05\right)$.
Cocaine: The distribution of adolescent/adult exposure was significantly different among bilateral, right, and left $\left(\mathrm{X}^{2}=6.764, \mathrm{p}<\right.$ $.05)$ or just right vs. left structures $\left(\mathrm{X}^{2}=5.730, \mathrm{p}<.02\right)$. More structures were affected in the right hemisphere.

Nicotine: The analysis showed no bilateral, right, and left or right vs. left distribution asymmetry due to the effect of adolescent/adult exposure to nicotine.

Cannabis: The analysis showed no bilateral, right, and left or right vs. left asymmetry due to the effect of adolescent/adult exposure to cannabis.

Opioids: The analysis showed no bilateral, right, and left or right vs. left asymmetry due to the effect of adolescent/adult exposure to opioids.

Alcohol: The analysis showed a marginal asymmetry for adolescent/ adult exposure to alcohol for bilateral, right, and left structures $\left(\mathrm{X}^{2}=\right.$ $4.688, \mathrm{p}<.10)$ due to a fewer number of bilateral structures affected; there was an equal number of mentions for the right and left hemisphere.

Table 2. Adolescent/adult exposure

\begin{tabular}{|c|c|c|c|c|c|}
\hline $\begin{array}{l}\text { DRUG/ } \\
\text { SIDE }\end{array}$ & $\begin{array}{c}\text { BILATERAL } \\
\text { (\# mentions } \\
\text { (\% of drug) }\end{array}$ & $\begin{array}{c}\text { LEFT } \\
\text { (\# mentions } \\
\text { (\% of drug) }\end{array}$ & $\begin{array}{c}\text { RIGHT } \\
\text { (\# mentions } \\
\text { (\% of drug) }\end{array}$ & $\begin{array}{c}\text { CHI- } \\
\text { SQUARE } \\
\text { (bilateral, } \\
\text { left, right) }\end{array}$ & $\begin{array}{c}\text { CHI- } \\
\text { SQUARE } \\
\text { (left, right; } \\
\text { bilateral } \\
\text { excluded) }\end{array}$ \\
\hline All drugs & $\begin{array}{l}98 \\
(29)\end{array}$ & $\begin{array}{c}109 \\
(32.2)\end{array}$ & $\begin{array}{c}131 \\
(38.8)\end{array}$ & $\begin{aligned} \mathrm{X}^{2} & =5.012 \\
\mathrm{p} & <.10\end{aligned}$ & $\begin{array}{c}\mathrm{X}^{2}=2.017 \\
\mathrm{NS}\end{array}$ \\
\hline Cocaine & $\begin{array}{c}26 \\
(29.2)\end{array}$ & $\begin{array}{c}22 \\
(24.7)\end{array}$ & $\begin{array}{c}41 \\
(46.1)\end{array}$ & $\begin{aligned} \mathrm{X}^{2} & =6.764 \\
\mathrm{p} & <.05\end{aligned}$ & $\begin{array}{c}\mathrm{X}^{2}=5.730 \\
\mathrm{p}<.02\end{array}$ \\
\hline Nicotine & $\begin{array}{c}18 \\
(25.4)\end{array}$ & $\begin{array}{c}31 \\
(43.7)\end{array}$ & $\begin{array}{c}22 \\
(31)\end{array}$ & $\begin{array}{c}\mathrm{X}^{2}=3.747 \\
\mathrm{NS}\end{array}$ & $\begin{array}{c}\mathrm{X}^{2}=1.528 \\
\mathrm{NS}\end{array}$ \\
\hline Cannabis & $\begin{array}{c}16 \\
(43.2)\end{array}$ & $\begin{array}{c}7 \\
(18.9)\end{array}$ & $\begin{array}{c}14 \\
(37.8)\end{array}$ & $\begin{array}{c}X^{2}=3.622 \\
\text { NS }\end{array}$ & $\begin{array}{c}\mathrm{X}^{2}=2.333 \\
\mathrm{NS}\end{array}$ \\
\hline Opioids & $\begin{array}{c}17 \\
(37.8)\end{array}$ & $\begin{array}{c}12 \\
(26.7)\end{array}$ & $\begin{array}{c}16 \\
(35.6\end{array}$ & $\begin{array}{c}\mathrm{X}^{2}=0.933 \\
\mathrm{NS}\end{array}$ & $\begin{array}{c}\mathrm{X}^{2}=0.571 \\
\mathrm{NS}\end{array}$ \\
\hline Alcohol & $\begin{array}{c}22 \\
(22.9)\end{array}$ & $\begin{array}{c}37 \\
(38.5)\end{array}$ & $\begin{array}{c}37 \\
(38.5)\end{array}$ & $\begin{aligned} \mathrm{X}^{2} & =4.688 \\
\mathrm{p} & <.10\end{aligned}$ & $\begin{array}{c}\mathrm{X}^{2}=0.0 \\
\mathrm{NS}\end{array}$ \\
\hline
\end{tabular}

Distribution: bilateral, left, right for cocaine, nicotine, cannabis, opioids, alcohol: $\mathrm{X}^{2}=$ $15.832 ; \mathrm{p}<.05$

Distribution: bilateral, left, right for cocaine, nicotine, cannabis, alcohol: $X^{2}=13.902 ; p<.05$ Distribution: bilateral, left, right for cocaine, nicotine, alcohol: $\mathrm{X}^{2}=7.559$; NS

Distribution: left, right for cocaine, nicotine, cannabis, opioids, alcohol: $\mathrm{X}^{2}=8.383 ; \mathrm{p}<.10$ Distribution: left, right for cocaine, nicotine, cannabis, alcohol: $\mathrm{X}^{2}=11.682 ; \mathrm{p}<.01$ Distribution: left, right for cocaine, nicotine, alcohol: $\mathrm{X}^{2}=6.751 ; \mathrm{p}<.05$

\section{Pre-natal Compared to Adolescent/adult Exposure (Table 3)}

The analysis showed no difference between pre-natal and adolescent/adult exposure for the distribution of structures affected among bilateral, right, and left or for just right vs. left structures for all drugs compiled together. In contrast, the distribution of asymmetric patterns of affected structures does differ among cocaine, cannabis, and alcohol depending on whether the exposure was pre-natal or as an adolescent/adult. This difference is the strongest for cocaine across bilateral, right, and left structures $\left(\mathrm{X}^{2}=5.25, \mathrm{p}<.10\right)$ and especially for right vs. left asymmetries $\left(\mathrm{X}^{2}=5.266, \mathrm{p}<.025\right)$. Pre-natal cocaine

Table 3. Distribution: prenatal vs. Adolescent/adult exposure

\begin{tabular}{|c|c|c|}
\hline DRUG/SIDE & $\begin{array}{c}\text { BILATERAL, LEFT, } \\
\text { RIGHT }\end{array}$ & LEFT vs. RIGHT \\
\hline All drugs & $\mathrm{X}^{2}=0.520(\mathrm{NS})$ & $\mathrm{X}^{2}=0.244(\mathrm{NS})$ \\
\hline Cocaine & $\mathrm{X}^{2}=5.25(\mathrm{p}<.10)$ & $\mathrm{X}^{2}=5.266(\mathrm{p}<.025)$ \\
\hline Nicotine & $\mathrm{X}^{2}=0.222(\mathrm{NS})$ & $\mathrm{X}^{2}=0.002(\mathrm{NS})$ \\
\hline Cannabis & $\mathrm{X}^{2}=11.548(\mathrm{p}<.01)$ & $\mathrm{X}^{2}=0.506(\mathrm{NS})$ \\
\hline Alcohol & $\mathrm{X}^{2}=4.14(\mathrm{NS})$ & $\mathrm{X}^{2}=2.833(\mathrm{p}<.10)$ \\
\hline
\end{tabular}


exposure tends to affect more structures in the left hemisphere while adolescent/adult exposure affects more structures in the right hemisphere. Essentially the reverse is true for alcohol for the right vs. left comparison $\left(\mathrm{X}^{2}=2.833, \mathrm{p}<.10\right)$ where pre-natal exposure affects more right hemisphere structures than left, while adolescent/ adult exposure affects the two hemispheres equally. For cannabis, the significant difference in asymmetry $\left(\mathrm{X}^{2}=11.548, \mathrm{p}<.01\right)$ between the pre-natal and adolescent/adult times of exposure for cannabis is due to the fact that the analysis showed no bilateral effects for prenatal exposure while there are several bilateral structures affected for adolescent/adult exposure. For nicotine, the analysis showed no difference between the laterality patterns between the pre-natal and adolescent/adult exposure times.

\section{Effect of Exposure on Brain Structures (Tables 4a and 4b)}

Pre-natal exposure to cocaine or to nicotine resulted in thinner cortices or smaller gray matter volumes. The few studies on cannabis reported thicker cortices or more gray matter volume. For alcohol, thinner or smaller volumes were reported about as often as larger volumes. fMRI studies reported less activation for cocaine exposure, more activation for nicotine and about equal reports of more or of less activation for cannabis or alcohol. For adolescent/adult exposure, there were considerably more reports of thinner or less gray matter volume after exposure to each of the drugs, except for cannabis. Most studies did not assess fMRI activation.

Table 4a. Effect of pre-natal exposure on brain structures

\begin{tabular}{|c|c|c|c|c|}
\hline $\begin{array}{l}\text { DRUG/ } \\
\text { EFFECT }\end{array}$ & $\begin{array}{l}\text { THINNER; } \\
\text { LESS GRAY } \\
\text { MATTER } \\
\text { VOLUME }\end{array}$ & $\begin{array}{l}\text { THICKER; } \\
\text { MORE GRAY } \\
\text { MATTER } \\
\text { VOLUME }\end{array}$ & $\begin{array}{c}\text { MORE } \\
\text { ACTIVE } \\
\text { (fMRI) }\end{array}$ & $\begin{array}{l}\text { LESS ACTIVE } \\
\text { (fMRI) }\end{array}$ \\
\hline Cocaine & 23 & 3 & 3 & 11 \\
\hline Nicotine & 17 & 1 & 24 & 13 \\
\hline Cannabis & 0 & 7 & 5 & 6 \\
\hline Alcohol & 22 & 25 & 8 & 9 \\
\hline
\end{tabular}

Table 4b. Effect of adolescent/adult exposure on brain structures

\begin{tabular}{|c|c|c|c|c|}
\hline DRUG/ & $\begin{array}{c}\text { THINNER; } \\
\text { LESS GRAY } \\
\text { MATTER } \\
\text { VOLUME }\end{array}$ & $\begin{array}{c}\text { THICKER; } \\
\text { MORE GRAY } \\
\text { MATTER } \\
\text { VOLUME }\end{array}$ & $\begin{array}{c}\text { MORE } \\
\text { ACTIVE } \\
\text { (fMRI) }\end{array}$ & $\begin{array}{c}\text { LESS ACTIVE } \\
\text { (fMRI) }\end{array}$ \\
\hline Cocaine & 69 & 8 & 6 & 6 \\
\hline Nicotine & 62 & 10 & -- & -- \\
\hline Cannabis & 21 & 18 & -- & -- \\
\hline Opioid & 39 & 6 & -- & -- \\
\hline Alcohol & 82 & 14 & -- & -- \\
\hline
\end{tabular}

\section{Discussion}

Exposure to some drugs of abuse appears to affect neural development but, depending on the drug and the time of exposure, the effects are distributed differently between the left and right hemispheres or bilaterally. This is true for both pre-natal and adolescent/adult exposure. Nevertheless, while the distribution pattern of asymmetries was significantly different across all drugs, only a few drugs had, themselves, a greater number of affected structures in one hemisphere or the other. Pre-natal exposure to alcohol resulted in a significantly greater number of affected structures in the right hemisphere reported more often than in the left. By contrast, the analysis showed no right/ left asymmetry for alcohol exposure in adolescent/adults, but the difference in distribution compared to pre-natal exposure approached significance. For cocaine there was a non-significant left hemisphere plurality of affected structures from pre-natal exposure but significantly more right hemisphere-structures were affected for adult exposure. The difference in distribution pattern between the pre-natal and adult exposure was significant. The analysis showed no significant right/left asymmetry for nicotine exposure for either pre-natal or adolescent/ adult exposure even though there were 50 percent more structures mentioned for the left hemisphere from both pre-natal and adolescent/ adult exposure.

Due to the observation that there are different consequences for neural development depending on the drug and the time of exposure, we can hypothesize that the drugs differentially affect the underlying neurobiological features of the development process. This is not new; the effects of drugs of abuse on neurosystems during development are elucidated in current literature. But the fact that the effects differ by hemisphere is not being studied but could provide additional clues of right/left asymmetries of neural development and how the drugs interact with different neurobiological systems. This is a missed opportunity since drugs that affect neural development should also asymmetrically affect the hemispheres-at least those demonstrated here. The following discussion reviews how those drugs affect neuronal development even though the question of hemispheric asymmetry is not addressed. This is followed by evidence that asymmetries do exist; research on the development of these asymmetries is lacking.

For the most part, when brain structures were affected, the result was smaller volumes, fewer neurons, or lower density. This was true for prenatal exposure to cocaine or nicotine and adult/adolescent exposure to these and the other drugs as well. Prenatal alcohol resulted in more studies reporting thicker or larger volumes than thinner or smaller volumes. Cellular level studies on the effects of prenatal drug exposure have used rodent-mainly mice-models with a few studies in nonhuman primates. A review of the effects of embryonic exposure to cocaine [7], suggested that cocaine's effect resulted from its interference of receptor signaling by monoamine neurons, mostly dopamine but possibly serotonin. Specifically, fetal exposure attenuates signaling of dopamine D1 receptors thereby shifting the balance of influence to D2 receptors which, in turn, inhibit migration of GABAergic neurons during embryonic development. Reduced numbers of neurons were observed in most cortical layers in both the ventral medial cortex and the somatosensory cortex [8]. These areas appear to coincide with areas of reduced gray matter in the left but not right hemisphere of humans in one of the studies [9] included in this survey. The review also suggested several other mechanisms, including cell death, resulting in reduced cell numbers which persist into adulthood. A more recent study [10] closely investigated mediating mechanisms that influence the GABA migration by prenatal cocaine exposure. Results identified a transient decrease in brain-derived neurotropic factor (BDNF) which is sensitive to receptor signaling and can modulate GABA migration. It was pointed out that, in the adult brain, BDNF is increased from cocaine exposure implying different influences depending on time of exposure.

The effect of prenatal nicotine on neurogenesis or neuron development appears to be more complicated with different results for different structures and differential neuron types. While neuronal decreases are most often reported, increases are reported as well. Reduction in neurons is consistent with the results reported here for the human subjects. As an example in the animal (mouse) model, one study reported fewer glutamatergic neurons [11] after prenatal exposure to nicotine due to disrupted proliferation of neuronal progenitors which ultimately resulted in a reduction of neurons in the medial prefrontal cortex. By contrast, prenatal exposure had a stimulatory effect on neurogenesis of orexigenic peptide-expressing neurons [12]. 
In contrast to the decreases most often reported for prenatal nicotine, there appeared to be generally more neuronal increases after prenatal alcohol exposure in the animal models. Such results would tend to support the greater volumes for prenatal exposure to alcohol in humans reported here as opposed to reduced structural volumes for the other drugs of abuse. The same research group reporting neurogenic stimulation following prenatal nicotine also reported stimulation of the same neurons following prenatal alcohol [13]. This finding of increased neurogenesis is supported by other studies (Ex., Skorput and Yeh [14].

A comprehensive review [15] described the effects on neurogenesis-mainly in the subgranular area of the hypothalamusby drugs of abuse from opioids to psychostimulants. Another review [16] focused specifically on the effect of adult exposure to cocaine for hippocampal neurogenesis in the rodent brain. It was concluded that cocaine suppressed adult hippocampus neurogenesis by reducing cell proliferation although the process was dynamic and would eventually normalize, perhaps by interaction with other mechanisms. It was also pointed out-again in the animal model-that reduced neurogenesis was a vulnerability factor for cocaine use. This suggestion was elegantly demonstrated in a comprehensive study [17] where neurogenesis was reduced in rats by radiation with the result that cocaine selfadministration was increased because cocaine was more reinforcing; vulnerability to relapse was also increased.

The survey results presented here demonstrate different laterality outcomes between prenatal and adult exposure. Yet, in the rodent models, there is no mention-likely no consideration-of laterality differences after exposure to drugs of abuse at any point in neuronal development. But lateral asymmetries of cell types related to neurotransmitters do exist. In an early study in one species of rats [18], there were greater levels of dopamine in the right anterior striatum, dorsolateral cortex and nucleus accumbens, although the striatum difference was not significant. Higher levels of serotonin were found in the left striatum and the right accumbens; however, greater serotonin turnover was in the left accumbens. Asymmetries of mechanisms of neurotransmitters can be induced by prenatal stress. Pregnant female rats produced offspring who had increased dopamine and a decrease in turnover rate in the right nucleus accumbens [19]. In another study, prenatal stress resulted in increased D2 receptors in both the left and right nucleus accumbens with an asymmetrically greater increase in the left [20]. The mechanism by which this asymmetry occurred was not mentioned, but stress increases cortisol. Experimental adult rats where cortisol was artificially increased resulted in reduced volume of the left anterior cingulate region [21]. These studies serve to demonstrate that there are asymmetries of neurotransmitter systems, even in rodents, and that these asymmetries can be achieved or modified by manipulations such as prenatal stress.

Finally, and most relevant for understanding addiction are studies demonstrating the effect of neurotransmitter asymmetries or unilateral lesions on the intake of addictive drugs. Rats were trained to selfadminister morphine followed by assays of dopamine metabolites (DOPAC and HVA) in three brain areas: nucleus accumbens, striatum, and medial prefrontal cortex [22]. Measures of self-administration were positively correlated with both metabolites and in both the left and right accumbens, negatively correlated in both left and right striatum, but positively correlated with only the right prefrontal cortex. In a similar paradigm in the same laboratory [23], rats were trained to selfadminister cocaine. The same negative correlations were found for the striatum, but for the prefrontal cortex, measures of self-administration were positively correlated with the metabolites in the left and negatively correlated in the right. Finally, in a study where dopamine projections in the medial prefrontal cortex were lesioned with 6-OHDA, significantly more ethanol was self-administered following a left lesion and significantly less ethanol was self-administered following a right lesion compared to controls. This study serves to demonstrate a differential relationship of intake of alcohol to neurotransmitters in the left or right medial prefrontal cortex in rodents.

An asymmetry of neuropeptides relevant for opioid addiction was reported in a recent study [24] in the post-mortem brains of healthy individuals. Leu-enkephalin-Arg, an agonist of delta and mu opioid receptors was lateralized to the left anterior cingulate cortex; Met-enkephalin-Arg-Phe, an agonist of kappa and mu receptors was lateralized to the right. Are these ratios different in persons with, or vulnerability for, opioid addiction? Would understanding of the laterality of these and other neurotransmitters and associated mechanism in each hemisphere aid in our understanding of opioid addiction? These are the kinds of questions that reflect a gap in addiction research.

\section{Conclusion}

According to the compilation of reports in this survey, some drugs of abuse differentially affect the development of structures in the left and right hemispheres of the brain. That is, there are more structures in the left or the right hemisphere that are thinner (or thicker) or have less gray matter volume depending on the drug and the time of exposure-prenatal or adolescent/adult. In the human studies there is no explanation of what underlying neurobiology produces these sized differences or the asymmetries. However, in the animal model, a large body of research focuses on the mechanisms by which drugs of abuse affect neurogenesis, among other mechanisms, to affect cell development, but there is no mention of laterality effects. Finally there are reports, again in the animal model, where induced lesions in one hemisphere or the other differentially affect self-administration of drugs of abuse. And finally, in both animals and humans some neurotransmitters are asymmetrically distributed. Right/left hemispheric differences have been studied in mental disorders, especially schizophrenia to understand the underlying mechanisms of the disorder, but not for addiction [25]. Data presented here for differential effects of drugs of abuse on the neurobiology of the left and right hemispheres as well as data presented previously [1] on right/ left hemispheric differences in neuronal activation for impulsivity and craving — risk factors for drug abuse - suggest that research focused on the differences in the left and right hemisphere would provide new insights to understanding the underlying factors of drug-seeking and addiction.

\section{Disclaimer:}

The views and opinions expressed in this manuscript are those of the author only and do not necessarily represent the views, official policy or position of the U.S. Department of Health and Human Services or any of its affiliated institutions or agencies.

\section{References}

1. Gordon HW (2016) Laterality of Brain Activation for Risk Factors of Addiction. Curr Drug Abuse Rev 9: 1-18. [Crossref]

2. de Ruiter MB, Oosterlaan J, Veltman DJ, van den Brink W, Goudriaan AE (2012) Similar hyporesponsiveness of the dorsomedial prefrontal cortex in problem gamblers and heavy smokers during an inhibitory control task. Drug Alcohol Depend 121: 8189. [Crossref]

3. Tapert SF, Schweinsburg AD, Drummond SP, Paulus MP, Brown SA, et al. (2007) Functional MRI of inhibitory processing in abstinent adolescent marijuana users. Psychopharmacology (Berl) 194: 173-183. [Crossref] 
4. Kaufman JN, Ross TJ, Stein EA, Garavan H (2003) Cingulate hypoactivity in cocaine users during a GO-NOGO task as revealed by event-related functional magnetic resonance imaging. J Neurosci 23: 7839-7843. [Crossref]

5. Blakemore SJ (2012) Imaging brain development: the adolescent brain. Neuroimage 61: 397-406. [Crossref]

6. Goddings AL, Mills KL, Clasen LS, Giedd JN, Viner RM, et al. (2014) The influence of puberty on subcortical brain development. Neuroimage 88: 242-251. [Crossref]

7. Bhide PG (2009) Dopamine, cocaine and the development of cerebral cortical cytoarchitecture: a review of current concepts. Semin Cell Dev Biol 20: 395-402. [Crossref]

8. James E Crandall, Hazel E Hackett, Stuart A Tobet, Barry E Kosofsky, Pradeep G. Bhide (2004) Cocaine exposure decreases GABA neuron migration from the ganglionic eminence to the cerebral cortex in embryonic mice. Cereb Cortex 14: p. 665-675. [Crossref]

9. Rando K, Chaplin TM, Potenza MN, Mayes L, Sinha R (2013) Prenatal cocaine exposure and gray matter volume in adolescent boys and girls: relationship to substance use initiation. Biol Psychiatry 74: 482-489. [Crossref]

10. McCarthy DM1, Zhang X, Darnell SB, Sangrey GR, Yanagawa Y, et al. (2011) Cocaine alters BDNF expression and neuronal migration in the embryonic mouse forebrain. $J$ Neurosci 31: 13400-13411. [Crossref]

11. Aoyama Y, Toriumi K, Mouri A, Hattori T, Ueda E (2016) Prenatal Nicotine Exposure Impairs the Proliferation of Neuronal Progenitors, Leading to Fewer Glutamatergic Neurons in the Medial Prefrontal Cortex. Neuropsychopharmacology 41: 578-589. [Crossref]

12. Chang GQ, Karatayev O, Leibowitz SF (2013) Prenatal exposure to nicotine stimulates neurogenesis of orexigenic peptide-expressing neurons in hypothalamus and amygdala. J Neurosci 33: 13600-13611. [Crossref]

13. Chang GQ, Karatayev O, Liang SC, Barson JR, Leibowitz SF (2012) Prenatal ethanol exposure stimulates neurogenesis in hypothalamic and limbic peptide systems: possible mechanism for offspring ethanol overconsumption. Neuroscience 222: 417-428. [Crossref]

14. Skorput AG, Yeh HH (2016) Chronic Gestational Exposure to Ethanol Leads to Enduring Aberrances in Cortical Form and Function in the Medial Prefrontal Cortex. Alcohol Clin Exp Res 40: 1479-1488. [Crossref]
15. Eisch AJ, Harburg GC (2006) Opiates, psychostimulants, and adult hippocampa neurogenesis: Insights for addiction and stem cell biology. Hippocampus 16: 271-286. [Crossref]

16. Castilla-Ortega E, Serrano A, Blanco E, Araos P, Suárez J, et al. (2016) A place for the hippocampus in the cocaine addiction circuit: Potential roles for adult hippocampal neurogenesis. Neurosci Biobehav Rev 66: 15-32. [Crossref]

17. Noonan MA, Bulin SE, Fuller DC, Eisch AJ (2010) Reduction of adult hippocampal neurogenesis confers vulnerability in an animal model of cocaine addiction. $J$ Neurosci 30: 304-315. [Crossref]

18. Rosen GD, Finklestein S, Stoll AL, Yutzey DA, Denenberg VH (1984) Neurochemical asymmetries in the albino rat's cortex, striatum, and nucleus accumbens. Life Sci 34: 1143-1148. [Crossref]

19. Alonso SJ, E Navarro, M Rodriguez (1994) Permanent dopaminergic alterations in the n. accumbens after prenatal stress. Pharmacol Biochem Behav 49: 353-358. [Crossref]

20. Adrover E, Berger MA, Pérez AA, Tarazi FI, Antonelli MC (2007) Effects of prenatal stress on dopamine D2 receptor asymmetry in rat brain. Synapse 61: 459-462. [Crossref]

21. Cerqueira JJ, Catania C, Sotiropoulos I, Schubert M, Kalisch R, et al. (2005) Corticosteroid status influences the volume of the rat cingulate cortex - a magnetic resonance imaging study. J Psychiatr Res 39: 451-460. [Crossref]

22. Glick SD, Merski C, Steindorf S, Wang S, Keller RW, et al. (1992) Neurochemical predisposition to self-administer morphine in rats. Brain Res 578: 215-220. [Crossref]

23. Glick S, Raucci J, Wang S, Keller RW Jr, Carlson JN (1994) Neurochemical predisposition to self-administer cocaine in rats: individual differences in dopamine and its metabolites. Brain Res 653: 148-154.

24. Watanabe H, Fitting S, Hussain MZ, Kononenko O, Iatsyshyna A, et al. (2015) Asymmetry of the endogenous opioid system in the human anterior cingulate: a putative molecular basis for lateralization of emotions and pain. Cereb Cortex 25: 97108. [Crossref]

25. Gordon HW (2016) Putting Hemispheric Asymmetry to Use in Understanding Brain Diseases. Journal of Systems and Integrative Neuroscience 3: 1-2. [Crossref]

Copyright: ( 2017 Gordon HW. This is an open-access article distributed under the terms of the Creative Commons Attribution License, which permits unrestricted use, distribution, and reproduction in any medium, provided the original author and source are credited. 